\title{
Fatores Associados à Síndrome de Burnout em Motoristas de Transporte Coletivo de Passageiros
}

\author{
Gabriela Cristine Neumann ${ }^{1 *}$, Mary Sandra Carlotto ${ }^{2}$
}

${ }^{1}$ http://orcid.org/0000-0002-9791-6909 / Universidade do Vale do Rio dos Sinos (UNISINOS), Brasil

2 http://orcid.org/0000-0003-2336-5224 / Universidade do Vale do Rio dos Sinos (UNISINOS), Brasil

\section{Resumo}

Este estudo tem por objetivo identificar os fatores associados às dimensões da Síndrome de Burnout em motoristas de transporte coletivo de passageiros em uma amostragem de duzentos e cinqüenta e oito profissionais. Os instrumentos utilizados foram: Questionário de dados sócio-demográficos e laborais, questionário da avaliação relacionado à Síndrome de Burnout pelo trabalho; questionário de estressores ocupacionais e sub-escalas da Escala de Estressores Psicossociais no Contexto Laboral. Os resultados obtidos identificaram um modelo constituído por variáveis sócio-demográficas (idade), laborais (tempo de profissão, tempo de jornada), estressores ocupacionais (escala de trabalho, condições ambientais, relacionamento com passageiros idosos, relacionamento com fiscais, risco de assaltos), estressores psicossociais (ambiguidade de papéis, pressão do grau de responsabilidade). Aponta-se a necessidade de ações voltadas para a prevenção da Síndrome de Burnout nessa categoria profissional, bem como a necessidade de formação e capacitações aos motoristas voltadas aos estressores identificados e ações com passageiros voltadas à valorização do profissional.

Palavras-chave: Burnout, estresse ocupacional, motoristas.

\section{Factors associated with Burnout Syndrome among drivers of collective passenger transportation}

Abstract

The purpose of this study was to identify the factors associated with Burnout Syndrome among a sample of 258 drivers of collective passenger transportation, who work in private transportation companies. For the collection of data, the Sociodemographic Data questionnaire, the Evaluation of Burnout Syndrome at Work questionnaire, the Occupational Stressors and Subscales of the Scale of Psychosocial Stressors in the Labor Context questionnaire, and labor data were all used. The results identified predictive models for the dimensions of SB constituted by sociodemographic variables (age), labor (time of profession, resting interval time), occupational stressors (work schedule, environmental conditions, relationship with elderly passengers, relationship with supervisors, risk of assaults), and psychosocial stressors (ambiguity roles, pressure of degree of responsibility). The results show that actions to prevent Burnout Syndrome are needed in this professional category, such as training for drivers focused on the identified stressors and actions with passengers aimed at valuing the professional.
Factores Asociados a la Síndrome de Quemarse por el Trabajo en Conductores de Transporte Colectivo de Pasajeros

Resumen

Ese estudio tiene por objetivo identificar los factores asociados a las dimensiones de la Síndrome de Quemarse en conductores de transporte colectivo de pasajeros en una muestra de doscientos cincuenta y ocho conductores. Los instrumentos utilizados fueron utilizados un cuestionario de datos socio demográficos y laborales; cuestionario de evaluación de la Síndrome de Quemarse por el trabajo (CESQT), Cuestionario de estresores ocupacionales y las sub escalas de la Escala de Estresores Psicosociales en el Contexto Laboral. Los resultados, obtenidos identificaron un modelo constituido por variables socio demográficas (edad), laborales (tiempo de profesión, tiempo de intervalo), estresores ocupacionales (escala de trabajo, condiciones ambientales, relacionamiento con pasajeros mayores, relacionamiento con fiscales, posibilidad de asaltos) y estresores psicosociales (ambigüedad de papeles, presión del grado de responsabilidad). Apunta-se la necesidad de acciones dirigidas hacia la prevención de la Síndrome de Quemarse en esa categoría profesional, bien como la necesidad de formaciones y capacitación a los conductores direccionados a los estresores identificados y acciones educativas que contribuyan para la valorización del profesional.

Palabras-clave: Síndrome de Quemarse por el Trabajo, estresores ocupacionales, motoristas. 20(3), 1089-1096. https://doi.org/10.17652/rpot/2020.3.19173 
A Síndrome de Burnout (SB) tem sido definida como um fenômeno psicossocial devido a estressores crônicos ocasionados no meio laboral (Maslach, Schaufeli, \& Leiter, 2001; Maslach \& Leiter, 2016). Segundo Gil-Monte (2005; 2011), a SB é uma experiência de caráter negativo, composta por cognições, emoções e atitudes negativas pertinentes ao próprio trabalho e às pessoas com as quais se necessita relacionar como parte das atribuições profissionais. As consequências dessas respostas podem gerar uma série de disfunções comportamentais, psicológicas e fisiológicas que pode ter repercussões nocivas às pessoas e para a organização.

O modelo de Gil-Monte (2005) da SB constitui-se de quatro dimensões: 1) Ilusão pelo trabalho, descrita como o desejo do trabalhador para o alcance das metas profissionais (avaliada de forma inversa); 2) Desgaste psíquico, caracterizado por sentimentos de exaustão emocional e desgaste físico; 3) Indolência, quando aparecem atitudes de indiferença para com as pessoas que necessitam ser atendidas no ambiente de trabalho; e 4) Culpa, sentimento de culpa decorrente da cobrança social sobre comportamentos não alinhados às expectativas acerca do papel profissional. A dimensão de culpa consiste em um acréscimo do modelo de Gil-Monte (2005) em relação ao modelo tradicional de Maslach, Schaufeli e Leiter (2001). Nesse sentido, as três primeiras dimensões avaliam SB; já a quarta dimesão serve para a identificação de casos mais graves da síndrome Gil-Monte (2005).

Os motoristas de transporte coletivo de passageiros estão diariamente expostos a diversos fatores estressores no trabalho (Alonso, Cendales, Gómes, \& Useche 2018; Useche, Cendales, Alonso, \& Serge, 2017). Esses impactam na saúde física e emocional causando prejuízos no seu desempenho na direção (Valarmathi, 2019).

Quanto aos estressores relacionados às condições externas, destacam-se: o trânsito lento devido aos congestionamentos (Mattos, Moraes, \& Pereira, 2015; Silva \& Zavarize, 2017; Zanelato \& Oliveira, 2008); lidar com motoristas de carro de passeio que não respeitam o código de trânsito brasileiro (Almeida, 2007; Mattos, Moraes, \& Pereira, 2015); motoqueiros que, muitas vezes, "cortam" a frente dos onibus e buzinam de maneira inadequada (Silva \& Zavarize, 2017; Zanelato \& Oliveira, 2003); ciclistas que não respeitam as normas de trânsito (Silva \& Zavarize, 2017) e pedestres que não respeitam a faixa de segurança e demais sinalizações (Nóbrega, 2015; Silva \& Zavarize, 2017); condições climáticas (calor na cabine, fortes chuvas, alagamento das vias) (Makowiec-Dabrowska et al., 2019; Zanelato \& Oliveira, 2004); dirigir em más condições das vias devido aos buracos e sinalização deficiente (Battiston et al., 2006; Nóbrega, 2015; Silva \& Zavarize, 2017); e, risco de acidentes (Nóbrega, 2015; Tavares, 2010; Zanelato \& Oliveira, 2003).

No que diz respeito aos estressores relacionados ao conteúdo do cargo, a literatura aponta para escala de trabalho, falta de rotina nos horários, não ter folgas em finais de semana (Oliveira \& Pinheiro, 2007; Tavares, 2010; Silva \& Zavarize, 2017; Zanelato \& Oliveira, 2004); excesso de paradas durante a viagem; más condições do veículo, falhas nos equipamentos, ruídos e vibrações (Oliveira, 2004; Tavares, 2010); medo de roubos e assaltos (Nóbrega, 2015; Tavares, 2010; Zanelato \& Oliveira, 2004); segurança dos passageiros e temor que estes sofram algum tipo de queda e machuquem-se (Almeida, 2002; Battiston et al., 2006; Silva \& Zavarize, 2017).

Quanto aos estressores interpessoais, foram identificados conflitos com passageiros no momento de embarque e desembarque destes (Almeida, 2007; Mattos, Moraes, \& Pereira, 2015; Oliveira \& Pinheiro, 2007; Silva \& Zavarize, 2017); com passageiros idosos devido à gratuidade em algumas linhas (há linhas nas quais as passagens são gratuitas, e em outras não, e, muitas vezes, os idosos querem entrar em linhas pagas sem realizar o pagamento) (Zanelato, 2008); conflito com superiores, em especial, os fiscais, internos e externos, e com o cobrador inte- grante de sua linha (Almeida, 2002; Silva \& Zavarize, 2017).

A profissão de motorista de transporte coletivo é considerada uma das mais estressantes (Silva \& Zavarize, 2017) e propensas a riscos de saúde (Serrano-Fernández, Boada-Grau, Robert-Sentís, Vigil-Colet, \& Assens-Serra, 2019). Nos EUA, segundo dados de 2012, do Bureau of Labor Statistics of the United States Department of Labor, essa profissão está entre as sete ocupações com maior risco de adoecimento, com taxa de incidência de afastamento por doença maior que 375 casos por 10 mil. Fatores estressores esses que podem levar à ocorrência da Síndrome de Burnout (Nóbrega, 2015; Useche, Alonso, Cendales, Autukevičiūtè, \& Serge, 2017).

Em pesquisa sobre a SB em motoristas de ônibus na Tailândia, desenvolvida por Chung e Wu (2012), os resultados apontaram que a SB é a principal causa de tensão e problemas de saúde para esses profissionais, sendo a segurança pública a maior fonte de preocupação para a categoria. Essa situação tem gerado absenteísmo e deixado os motoristas mais propensos a envolverem-se em acidentes no trânsito. Investigação realizada entre motoristas da cidade de Santiago, no Chile, relatou associação entre Burnout e sobrecarga mental (Olivares, Wilke, Mena, \& Lavarello, 2013).

No Brasil, investigação realizada por Nóbrega (2015), com motoristas de transporte coletivo da cidade de "Coronel João Pessoa/RN", individuou associação significativa entre a presença de risco da $\mathrm{SB}$ e motoristas casados, com um ou dois filhos, naqueles que possuíam de 1 a 5 anos de profissão e em participantes envolvidos em algum acidente ocorrido nos últimos dois anos.

A partir do exposto, verificou-se que as características do trabalho do motorista de transporte coletivo expõem esse profissional a diversos fatores estressores que podem levar à ocorrência de SB. Assim, este estudo - de delineamento exploratório, observacional, analítico e transversal - objetivou identificar os fatores associados às dimensões da Síndrome de Burnout em motoristas de transporte coletivo de passageiros.

\section{Método}

\section{Participantes}

Foram convidados a participar do estudo todos os 340 motoristas de transporte coletivo de passageiros de duas empresas desse ramo, situadas em uma cidade do interior da região sul do Brasil. Responderam ao estudo 258 motoristas, caracterizando-se por uma amostra de conveniência, correspondendo a $76 \%$ da população. Foram considerados os seguintes critérios de inclusão: estar em atividade profissional de motorista de coletivo há pelo menos seis meses na mesma empresa. Todos os participantes eram do sexo masculino, sendo a maior parte de estado civil casado (60,3\%), com filhos $(63,3 \%)$ e apresentava escolaridade em nível de Ensino Médio completo (62,0\%). A idade variou entre 20 a 67 anos $(M=40,70$; $D P=10,922)$. No que tange aos dados laborais, a maior parcela dos motoristas estava entre 1 a 5 anos na mesma empresa $(38,8 \%)$, enquanto $29,1 \%$ estavam a mais de 10 anos na mesma empresa.

\section{Instrumentos}

1) Questionário de dados sociodemográficos. Questionário com itens sobre Idade (anos), situação conjugal (com companheira(o), sem companheira(o), filhos (sim/não), escolaridade (Ensino Fundamental/Ensino Médio/Superior).

2) Questionário de dados laborais. Questionário com itens sobre tempo de profissão (anos), tempo de sua intrajornada (menos de uma hora/mais de uma hora), período em que trabalha (manhã/tarde/noite). 
3) Cuestionario para la Evaluación Síndrome de Quemarse por el Trabajo - CESQT (Gil-Monte, 2005). Adaptado, para o uso no Brasil, por Gil-Monte, Carlotto e Câmara (2010) com a devida adaptação da redação dos itens de acordo com a população-alvo, no caso substituindo a palavra "alunos" pela palavra "pessoas" de relacionamento do contexto laboral. Esse é composto por 20 itens que foram avaliados por uma escala de frequência de 5 graus, variando de 0 (nunca) a 4 (muito frequentemente: todos os dias). Os itens são distribuídos em quatro subescalas assim denominadas: a. Ilusão para o trabalho: refere-se ao desejo de atingir metas de trabalho percebidas como fonte de prazer e realização pessoal. As pontuações baixas indicariam altos níveis da SB (exemplo de item: vejo meu trabalho como uma fonte de realização pessoal); b. Desgaste psíquico: avalia a exaustão emocional e física causada pelo contato contínuo com pessoas que apresentam ou causam problemas ( 4 itens, alfa $=$ 0,87 ) (exemplo de item: sinto-me desgastado emocionalmente); c. Indolência: atitudes negativas como a insensibilidade, a indiferença, o cinismo tanto em relação ao trabalho e quanto aos clientes da organização ( 6 itens, alfa $=0,76)$ (exemplo de item: acho meus clientes desagradáveis); d. Culpa: esta dimensão refere-se ao sentimento de culpa desenvolvido pelos trabalhadores ligados à crença de que eles não têm um comportamento positivo e adequado em seu trabalho, bem como à falta de sucesso profissional (5 itens, alfa $=0,79$ ) (exemplo de item: Eu tenho remorso por alguns dos meus comportamentos no trabalho).

4) Subescalas da Escala de Estressores Psicossociais no Contexto Laboral (Ferreira et al., 2015). As seis subescalas totalizam 31 itens: 1 . Conflito e ambiguidade de papéis: definida como a falta de clareza sobre as próprias funções e ao recebimento de demandas contraditórias sobre as funções desempenhadas (cinco itens, $\alpha=0,77$ ) (exemplo de item: Recebo instruções contraditórias sobre o que fazer no trabalho); 2 . Sobrecarga de papéis: consiste no excesso de tarefas que o empregado é solicitado, por vezes, a desempenhar (seis itens, $\alpha=0,71$ ) (exemplo de item: Realizo várias tarefas ao mesmo tempo); 3 . Falta de suporte social: avalia as dificuldades advindas da falta de suporte emocional recebido pelos colegas e superiores, no cotidiano do trabalho (seis itens, $\alpha=$ 0,77 ) (exemplo de item: Não sou ouvido por meus colegas quando tenho dificuldades no trabalho); 4. Falta de autonomia: caracteriza-se pelas dificuldades de planejar e tomar decisões acerca das suas próprias tarefas (cinco itens, $\alpha=0,71$ ) (exemplo de item: Não posso estabelecer meu próprio ritmo de trabalho); 5 . Conflito trabalho-família: avalia a percepção de incompatibilidade entre as responsabilidades associadas à família e ao trabalho (cinco itens, $\alpha=0,75$ ) (exemplo de item: Não disponho de tempo para minha vida familiar em função do trabalho); 6. Pressão do grau de responsabilidade: caracteriza-se pelo sentimento de responsabilidade acerca de pessoas e de equipamentos que o empregado utiliza para o desempenho de suas funções (quatro itens, $\alpha=0,77$ ) (exemplo de item: Saber que meus erros podem interferir negativamente na vida de outras pessoas). Todos os itens foram avaliados por meio de uma escala de frequência de cinco pontos (zero "nunca" a 4 "diariamente"). Todos o itens são avaliados com uma escala de frequência de seis pontos (1 "nunca me afeta" a 6 "sempre me afeta").

5) Questionário de estressores ocupacionais para motoristas de transporte coletivo de passageiros. Elaborado para o presente estudo com base na literatura, sobre estressores em motoristas de transporte coletivo de passageiros (Lámbarry, 2016; Oliveira \& Pinheiro, 2007; Silve \& Zavarize, 2017; Tse \& Flin, 2006; Zanellato, 2008). Apresenta 10 itens para poder avaliar: 1. Condições ambientais (alagamentos, enchentes); 2. Condições da estrada (buracos, falta de sinalizações); 3. Relacionamento motorista-cobrador (conflitos); 4. Relacionamento com passa- geiros (reclamações); 5. Relacionamento com fiscais da empresa (pressões); 6. Escala de trabalho; 7. Riscos de assaltos e roubos; 8. Congestionamentos no trânsito; 9. medo de se envolver em acidentes; 10. medo de se envolver em acidentes; 11. Trafegar entre motociclistas e ciclistas (que não seguem as normas de trânsito). A avaliação dos itens foi realizada por meio de uma escala de cinco pontos (0 "nada estressante" a 4 "muito estressante").

\section{Procedimento de Coleta de Dados e Cuidados Éticos}

Inicialmente, contatou-se a direção das empresas para obtenção da anuência e apoio logístico para a realização do estudo. Após, cartazes foram colocados para divulgação do estudo e dos objetivos. Posteriormente, foram entregues os questionários e o Termo de Consentimento Livre e Esclarecido (TCLE) nos setores que os motoristas frequentavam, bem como os procedimentos para o preenchimento dos dados, com a orientação de que duas urnas seriam disponibilizadas, esclarecendo que o instrumento deveria ser depositado em uma urna; sendo uma para o depósito dos questionários, e a outra para o TCLE. O período de realização da coleta ocorreu entre os meses de setembro a dezembro de 2018. O estudo foi aprovado pelo Comitê de Ética em Pesquisa da [nome da instituição omitido visando preservar o sistema de double blind review] sob o número CAAE: 94871018.7.000.5344.

\section{Procedimento de Análise de Dados}

O banco de dados foi analisado por meio do Statistical Package for the Social Sciences (SPSS, versão 20.0). Inicialmente, foram executadas análises descritivas de caráter exploratório visando avaliar a distribuição dos itens, a presença de casos omissos e possíveis erros de digitação dos dados. Tal estatística também foi utilizada para a caracterização da amostra.

Os pressupostos para a análise de regressão linear foram testados, sendo identificados valores aceitáveis de acordo com Field (2009). Foi verificada ausência de multicolinearidade, pois todos os valores das correlações ficaram abaixo de 0,676, os valores de Variance Inflation Factor (VIF) situaram-se abaixo de quatro (variação de 1,994 a 2,048); e os valores de tolerância foram inferiores a um (variação de 0,991 a 0,997 ). A análise do coeficiente de Durbin-Watson identificou valores próximos a dois (variação de 1,718 a 2,044), desse modo, assinalando a independência da distribuição e a não correlação dos resíduos. A distância de Cook apresentou valor de 0,007, inferior a um, indicando não existir preditores atípicos e um adequado ajuste dos modelos.

Para identificar os preditores foi realizada análise de regressão linear múltipla, método Stepwise. O modelo proposto estabelece a SB como variável dependente (VD), considerando suas quatro dimensões - Ilusão pelo trabalho, Desgaste psicológico, Indolência, Culpa - e as demais variáveis como independentes (VIs). A magnitude do efeito (effect size) foi avaliada pelos coeficientes de regressão padronizados de cada modelo final, de acordo com Marôco, (2007). O tratamento dos dados considerou um nível de confiança de $95 \%$ com um nível de significância de 5\% (valor de $p \leq 0,05$ ).

\section{Resultados}

$\mathrm{Na}$ Tabela 1, estão elencados os resultados da análise descritiva da amostra no tocante às dimensões da $\mathrm{SB}$, dos estressores psicossociais e dos estressores ocupacionais. $\mathrm{O}$ índice mais elevado, indicativo da síndrome, considerando a escala de pontuação, foi na dimensão de Culpa. Quanto aos estressores psicossociais, o maior índice foi apresentado na dimensão de Sobrecarga de papéis, e o estressor ocupacional de maior média foi a Riscos de 
Média, desvio padrão e pontuação das dimensões dos instrumentos utilizados e alfas obtidos na presente amostra.

\begin{tabular}{|c|c|c|c|c|}
\hline Variáveis & Escala & M & $D P$ & $\alpha$ \\
\hline Síndrome de Burnout & $0-4$ & & & \\
\hline Ilusão pelo trabalho & & 2,87 & 0,82 & 0,83 \\
\hline Desgaste psíquico & & 1,24 & 0,96 & 0,86 \\
\hline Indolência & & 1,07 & 0,89 & 0,89 \\
\hline Culpa & & 1,38 & 0,83 & 0,81 \\
\hline Estressores psicossociais/contexto laboral & $1-6$ & & & \\
\hline Ambiguidade de papéis & & 1,04 & 0,71 & 0,70 \\
\hline Sobrecarga de papéis & & 2,66 & 0,69 & 0,63 \\
\hline Falta de suporte social & & 1,93 & 0,78 & 0,83 \\
\hline Falta de autonomia & & 1,27 & 0,79 & 0,70 \\
\hline Conflito trabalho família & & 1,93 & 0,58 & 0,76 \\
\hline Pressão do grau de responsabilidade & & 2,06 & 1,28 & 0,92 \\
\hline Estressores ocupacionais & $1-4$ & & & \\
\hline 1 Condições ambientais & & 1,99 & 0,83 & \\
\hline 2 Condições da estrada & & 2,27 & 0,78 & \\
\hline 3 Relacionamento motorista-cobrador & & 1,75 & 0,86 & \\
\hline 4 Relacionamento com passageiros & & 1,87 & 0,87 & \\
\hline 5 Relacionamento com fiscais da empresa & & 1,84 & 0,94 & \\
\hline 6 Escala de trabalho & & 2,17 & 1,07 & \\
\hline 7 Riscos de assaltos e roubos & & 2,60 & 0,88 & \\
\hline 8 Congestionamentos no trânsito & & 2,42 & 0,81 & \\
\hline 9 Medo de se envolver em acidentes & & 2,50 & 0,81 & \\
\hline 10 Trafegar entre motociclistas e ciclistas & & 2,13 & 0,85 & \\
\hline
\end{tabular}

Nota. 1. Condições ambientais (alagamentos, enchentes); 2. Condições da estrada (buracos, falta de sinalizações); 3. Relacionamento motorista-cobrador (conflitos); 4. Relacionamento com passageiros (reclamações); 5. Relacionamento com fiscais da empresa (pressões); 6. Escala de trabalho; 7. Riscos de assaltos e roubos; 8 . Congestionamentos no trânsito; 09 . medo de se envolver em acidentes; 10. Trafegar entre motociclistas e ciclistas (que não seguem as normas de trânsito).

assaltos e roubos. Todas as dimensões apresentaram coeficientes de consistência interna, que foram obtidos por meio do coeficiente alfa de Cronbach, considerados satisfatórios $(\alpha>0,70)$.

Resultados obtidos por meio da análise de regressão linear múltipla, método Stepwise (Tabela 2) - que considerou as dimensões de Burnout como variáveis dependentes e, como variáveis preditoras, as variáveis sociodemográficas, laborais e psicossociais - , revelaram um modelo preditor para a dimensão de Ilusão pelo trabalho, constituído pelas variáveis escala de trabalho, sobrecarga de papéis, tempo de intrajornada, condições ambientais, conflito e ambiguidade de papéis e idade que, conjuntamente, explicaram $32,8 \%$ dessa dimensão. Assim, quanto maior a percepção de que a escala de trabalho e as condições ambientais (calor e alagamento das vias), a ambiguidade de papéis e a sobrecarga de papéis são estressantes, menor é o desejo individual para o alcance das metas profissionais. Quanto maior a percepção do menor tempo de intrajornada e mais elevada a idade, maior é a Ilusão pelo trabalho.

Com relação ao Desgaste psíquico, o conjunto de variáveis preditoras explicou $45,1 \%$ da variabilidade desta dimensão, sendo seus estressores: escala de trabalho, pressão do grau de responsabilidade, a ambiguidade de papéis, a relação com os passageiros idosos, a idade e a possibilidade de assaltos. Nesse sentido, quanto maior a percepção dos estressores escala de trabalho, relação com idosos, possibilidade de assalto, ambiguidade de papéis, pressão do grau de responsabilidade, maior o sentimento de Desgaste Psicológico, tendo esta dimensão diminuída com a elevação da idade dos motoristas.

No que tange à dimensão de Indolência, as variáveis preditoras foram os estressores relacionamento com os fiscais da empresa, a pressão do grau de responsabilidade, a escala de trabalho, a ambiguidade de papéis, o tempo de profissão e o tempo de interjornada. Esse conjunto de variáveis apresentou um poder explicativo de $48 \%$. Os resultados indicam que quanto maior a percepção de que o relacionamento estabelecido com os fiscais da empresa, a pressão pela responsabilidade, a escala de trabalho e a ambiguidade de papéis são estressantes e quanto menor o tempo de interjornada, maior é o sentimento de distanciamento da clientela.

Por fim, para a dimensão Culpa, a análise revelou como preditores os estressores relacionamento com os fiscais, pressão da responsabilidade e tempo de profissão, que, em conjunto, apresentaram um poder explicativo de $22,8 \%$. Nesse sentido, quanto mais elevada a percepção de que o relacionamento com os fiscais e a pressão por responsabilidade são estressantes, maior é o sentimento de culpa, sendo que este diminui com o maior tempo de profissão.

A magnitude do efeito das variáveis independentes sobre as dimensões da SB apresentou uma variação de moderada $\left(R^{2}=0,228\right)$ à elevada $\left(R^{2}=0,480\right)$, de acordo com Field (2009). Assim, de acordo com o autor, as relações encontradas, possivelmente, também estejam presentes na população-alvo.

\section{Discussão}

O presente estudo buscou identificar o poder preditivo das variáveis sociodemográficas, laborais e psicossociais para as dimensões da SB em motoristas de transporte coletivo de passageiros. Para atender ao objetivo, os resultados foram discutidos para cada dimensão da SB.

Quanto à dimensão de Ilusão pelo trabalho, verificou-se que esta diminuiu com o aumento da percepção dos estressores escala de trabalho, condições ambientais (calor, alagamento das vias), ambiguidade de papéis e sobrecarga de papéis. As variáveis maior tempo de intrajornada e idade do motorista aumentam o desejo desse trabalhador para o alcance das metas profissionais.

O resultado relativo à escala de trabalho pode ser explicado pelas características da organização do trabalho das empresas de transporte coletivo, pois elas possuem extensa e instável carga ho- 


\begin{tabular}{|c|c|c|c|c|c|c|c|}
\hline Variáveis & $R$ & $R^{2}$ Adj & $B$ & SE & $\beta$ & $t$ & $p$ \\
\hline \multicolumn{8}{|l|}{ Ilusão pelo Trabalho } \\
\hline 1. Escala de trabalho & 0,444 & 0,193 & $-0,231$ & 0,058 & $-0,293$ & $-4,008$ & $0,000^{* *}$ \\
\hline 2. Sobrecarga de trabalho & 0,503 & 0,245 & 0,261 & 0,072 & 0,224 & 3,641 & $0,000^{* *}$ \\
\hline 3. Intrajornada & 0,532 & 0271 & 0,358 & 0,107 & 0,211 & 3,351 & $0,001 * *$ \\
\hline 4. Condições ambientais & 0,558 & 0,296 & $-0,193$ & 0,069 & $-0,196$ & $-2,783$ & $0,006^{* *}$ \\
\hline 5. Ambiguidade de papéis & 0,575 & 0,311 & $-0,172$ & 0,071 & $-0,152$ & $-2,408$ & $0,017 *$ \\
\hline 6. Idade & 0,591 & 0,328 & 0,011 & 0,005 & 0,144 & 2,305 & $0,022^{*}$ \\
\hline Modelo F & & & 15,942 & & & & \\
\hline \multicolumn{8}{|l|}{ Desgaste Psíquico } \\
\hline 1. Escala de trabalho & 0,535 & 0,282 & 0,275 & 0,069 & 0,294 & 3,986 & $0,000^{* *}$ \\
\hline 2. Pressão/responsabilidade & 0,608 & 0,362 & 0,150 & 0,047 & 0,196 & 3,171 & $0,002 * *$ \\
\hline 3. Ambiguidade de papéis & 0,645 & 0,406 & 0,300 & 0,079 & 0,223 & 3,779 & $0,000^{* *}$ \\
\hline 4. Relação c/passageiros idosos & 0,661 & 0,425 & 0,229 & 0,077 & 0,226 & 2,988 & $0,003 * *$ \\
\hline 5. Idade & 0,675 & 0,441 & $-0,012$ & 0,005 & $-0,133$ & $-2,330$ & $0,021 *$ \\
\hline 6. Possibilidade de assaltos & 0,685 & 0,451 & 0,135 & 0,064 & 0,118 & 2,109 & $0,036^{*}$ \\
\hline Modelo F & & & 26,217 & & & & \\
\hline \multicolumn{8}{|l|}{ Indolência } \\
\hline 1. Relacionamento com os fiscais & 0,573 & 0,325 & 0,326 & 0,073 & 0,320 & 4,444 & $0,000 * *$ \\
\hline 2. Pressão/responsabilidade & 0,646 & 0,410 & 0,157 & 0,042 & 0,217 & 3,705 & $0,000^{* *}$ \\
\hline 3. Escala de trabalho & 0,668 & 0,437 & 0,193 & 0,066 & 0,218 & 2,926 & $0,004 * *$ \\
\hline 4. Ambiguidade de papéis & 0,686 & 0,459 & 0,235 & 0,074 & 0,184 & 3,168 & $0,002 * *$ \\
\hline 5. Tempo de profissão & 0,697 & 0,471 & $-0,128$ & 0,063 & $-0,109$ & $-2,022$ & $0,045^{*}$ \\
\hline 6. Intrajornada & 0,705 & 0,480 & $-0,211$ & 0,106 & $-0,111$ & $-2,000$ & $0,047^{*}$ \\
\hline Modelo F & & & 29,290 & & & & \\
\hline \multicolumn{8}{|l|}{ Culpa } \\
\hline 1. Relacionamento c/fiscais & 0,420 & 0,172 & 0,350 & 0,062 & 0,379 & 5,639 & $0,000^{* *}$ \\
\hline 2. Responsabilidade & 0,468 & 0,210 & 0,139 & 0,044 & 0,212 & 3,172 & $0,002^{* *}$ \\
\hline 3. Tempo de profissão & 0,491 & 0,228 & $-0,159$ & 0,069 & $-0,150$ & $-2,307$ & $0,022^{*}$ \\
\hline Modelo F & & & 31,818 & & & & \\
\hline
\end{tabular}

Nota. $* p \leq 0,05 ; * * p \leq 0,01 * * * p \leq 0,000$

rária de trabalho para o motorista devido à prestação dos serviços ocorrer, também, em finais de semana e feriados, ou ainda em razão de horários que iniciam no turno da manhã e encerram na madrugada (Battiston, Cruz, \& Hoffmann, 2006). O horário de trabalho estabelecido pelas empresas é a maior fonte do estresse ocupacional de motoristas (Oliveira \& Pinheiro 2007). Em razão dos períodos de descanso e intrajornada exigidas pelas leis trabalhistas brasileiras, muitos motoristas não possuem horários efetivos, tendo dificuldades em organizar a sua rotina (Oliveira \& Pinheiro, 2007; Silva \& Zavarize, 2017; Tavares, 2010; Zanelato \& Oliveira, 2004).

Os motoristas também são obrigados a cumprir escala de viagens com horários preestabelecidos, independente das condições de trânsito, meteorológicas ou qualquer outra dificuldade que possa impactar no cumprimento da tabela de horários (Liberal, Saburido, \& Souza, 2016). As condições climáticas que interferem no trabalho do motorista, tais como o calor, alagamentos das vias e/ou a ventilação interna do ônibus, impactam negativamente na Ilusão pelo trabalho. É importante destacar que, na maioria dos ônibus, o motor é localizado ao lado do assento do motorista, o que eleva a temperatura interna do local de trabalho, assim como o número de passageiros dificulta a ventilação, desse modo, aumenta a sensação de calor e desconforto (Farina, Lopes, \& Martins, 2014). Nesse sentido, pode-se inferir que os motoristas, ao não ter controle sobre seu trabalho em termos de horários, condições físicas e climáticas, passam a desenvolver um sentimento de não estar atingindo suas metas profissionais e de que o trabalho não é fonte de prazer e realização pessoal.

Somam-se a esses estressores, o conflito e a ambiguidade de papéis e a sobrecarga de papéis, pois, em várias ocasiões, os motoristas precisam fazer mais que as atividades prescritas ao seu cargo. O motorista, também, necessita realizar a cobrança da passagem em valores ou vales-transportes, modalidade de dirigir e cobrar que vem aumentando nos últimos anos, carregar bagagens, além de zelar pelo bom andamento da viagem, para tanto, adotando medidas de prevenção ou solução de qualquer problema para garantir o bem-estar dos passageiros, pedestres e de outros veículos, de acordo com a Classificação Brasileira de Ocupações (CBO, 2015). As condições inadequadas de trabalho têm sido apontadas como importantes fatores de estresse para esses profissionais (Moraes, Santorum, Souza, Ávila, \& Vieira, 2017). Assim, pode-se pensar que esses estressores, relacionados à organização e às condições do trabalho dificultam o desejo do trabalhador para o alcance das metas profissionais.

O tempo de intrajornada associou-se positivamente com a Ilusão pelo trabalho. A Lei n. ${ }^{\circ}$ 12.619/2012 refere-se ao trabalho efetivo como o tempo que o motorista se mantém à disposição do empregador, excluídos os intervalos para refeição, repouso, espera e descanso. Ao motorista profissional fica assegurado o intervalo mínimo de uma hora para refeição, além de intervalo de repouso, diário, de onze horas a cada vinte e quatro horas, bem como descanso, semanal, de trinta e cinco horas. Devido à grade de horários de inúmeros itinerários, muitas vezes, esse intervalo alonga-se por até quatro horas, fazendo com que o motorista reste na rodoviária, ou em local indicado pela empresa. Nesse período, o profissional costuma fazer suas refeições ou lanches e descansar (Battiston, Cruz, \& Hoffmann, 2006). Como a relaciona-se positivamente com 
a ilusão, detectou-se que os motoristas aproveitam tais momentos para socializar, pois, ao conviver com colegas, criam um espaço de lazer e companheirismo, visto que sua profissão é bastante solitária, porque, mesmo transportando muitas pessoas, eles ficam isolados em suas cabines. Segundo os autores, a relação estabelecida entre os motoristas e seus colegas de trabalho, tanto cobradores quanto outros motoristas, caracteriza-pela solidariedade e companheirismo por compartilharem as mesmas condições de trabalho.

A idade do motorista relacionou-se de forma positiva com a Ilusão pelo trabalho, sendo assim, quanto mais idade o motorista possuía, mais engajado para alcançar suas metas no trabalho. Este resultado está alinhado ao estudo de Bigatão (2005), que verificou que o motorista mais jovem revelava mais estresse e concluiu que o motorista, na fase inicial da sua profissão, provavelmente, precisa adaptar-se a novas situações até adquirir um domínio maior da sua atividade. A idade, a maturidade, a estabilidade na carreira e a experiência adquirida com os anos de trabalho acarretam uma diminuição do estresse, com isso, aumentando a autoconfiança (Souza et al., 2016), isso tendo impacto positivo na busca de metas e realização no trabalho.

A dimensão Desgaste psíquico foi explicada pela elevação da percepção do estressor Relacionamento com passageiros idosos, que, segundo os motoristas, possuem dificuldades para executar o embarque e desembarque, muitas vezes, atrasando o horário, fazem as mesmas perguntas todos os dias, apresentam algumas limitações e, algumas vezes, chegam embriagados (Zanelato, 2008). Além dessas questões, em diversas linhas, as pessoas com mais de 65 anos têm direito à gratuidade, mas, para gozar desse benefício, é exigido deles alguns documentos como carteira do idoso ou de identidade. Há, ainda, algumas linhas que o número de idosos com desconto é limitado, de acordo com a lei estadual para linhas urbanas n. ${ }^{\circ}$ 4.022/03, doc. n. ${ }^{\circ} 7$, que estabelece gratuidade para apenas dois idosos, em caso de um terceiro, este precisará pagar a passagem integral, o que termina fazendo-lhes pensar que o motorista esteja tentando impedir o embarque do idoso, o que revolta os demais passageiros, que, não raras vezes, passam a agredir verbalmente esse profissional. Esse resultado corrobora a pesquisa de Lima, Lima e Silva (2018), na qual 35\% dos motoristas entrevistados afirmaram que se sentem cansados em trabalhar com pessoas.

Outro estressor que eleva o desgaste psíquico é os riscos de assaltos, pois os motoristas estão sujeitos à violência urbana. Esses lidam com todo o tipo de público e, assim, não possuem controle sobre quem estão transportando, o que exige estado de vigília permanente (Matias \& Sales, 2017; Torres, 2018).

A dimensão Desgaste psíquico foi explicada pelas variáveis escala de trabalho, pressão/responsabilidade, ambiguidade de papéis, relacionamento com os passageiros idosos, idade e a possibilidade de assaltos. Como o desgaste psíquico é caracterizado pelo surgimento de esgotamentos emocional e físico decorrentes de ter de lidar, diariamente, em seu trabalho, com pessoas que apresentam ou causam problemas (Gil-Monte, 2005). A escala de trabalho é explicada nesta variável pelo fato de ser incerta (alternando todos os dias), não permitindo um planejamento social ou familiar ao motorista (Battiston, Cruz, \& Hoffmann, 2006) podendo gerar um esgotamento . Assim como o fato deste profissional transportar vidas, causando uma grande pressão e responsabilidade ao mesmo, fazendo com que tenha que estar sempre alerta (Torres, 2018). A percepção do estressor Relacionamento com passageiros idosos, que, segundo os motoristas, possuem dificuldades para executar o embarque e desembarque, muitas vezes, atrasando o horário, fazem as mesmas perguntas todos os dias, apresentam algumas limitações e, algumas vezes, chegam embriagados (Zanelato, 2008). Além dessas questões, em diversas linhas, as pessoas com mais de 65 anos têm direito à gratuidade, mas, para gozar des- se benefício, é exigido deles alguns documentos como carteira do idoso ou de identidade. Há, ainda, algumas linhas que o número de idosos com desconto é limitado, de acordo com a lei estadual para linhas urbanas n. ${ }^{\circ}$ 4.022/03, doc. n. ${ }^{\circ} 7$, que estabelece gratuidade para apenas dois idosos, em caso de um terceiro, este precisará pagar a passagem integral, o que termina fazendo-lhes pensar que o motorista esteja tentando impedir o embarque do idoso, o que revolta os demais passageiros, que, não raras vezes, passam a agredir verbalmente esse profissional. Esse resultado corrobora a pesquisa de Lima, Lima e Silva (2018), na qual 35\% dos motoristas entrevistados afirmaram que se sentem cansados em trabalhar com pessoas.

A ambiguidade de papeis gera um esgotamento ao motorista, uma vez que o mesmo, necessita fazer muito mais que dirigir, dar informações aos passageiros, por vezes dirigir e cobrar, manter a ordem no ônibus entre outras funções (Moraes, Santorum, Souza, Ávila, \& Vieira, 2017). Outro estressor que eleva o desgaste psíquico é os riscos de assaltos, pois os motoristas estão sujeitos à violência urbana. Esses lidam com todo o tipo de público e, assim, não possuem controle sobre quem estão transportando, o que exige estado de vigília permanente (Matias \& Sales, 2017; Torres, 2018). Quanto à idade, verificou-se que sua elevação diminui o desgaste psíquico. Este resultado pode ser explicado pelo fato de que os motoristas vão adquirindo maior experiência profissional o que os deixariam mais seguro de suas ações frente às demandas da profissão (Carlotto \& Câmara, 2007; Dallacosta, 2014)

A Indolência teve, como variável que apresentou maior importância relativa nessa dimensão, o estressor Relacionamento com os fiscais. A principal forma de controle do trabalho dos motoristas são os fiscais das próprias organizações, que são responsáveis por conferir o itinerário das linhas, verificar o desenvolvimento do serviço, o cumprimento dos horários e das normas estabelecidas pela da empresa (Matias \& Sales, 2017). Então, a organização do trabalho, na linha e nos terminais, acontece a partir desses fiscais, que se localizam nos pontos de controle com a função de registrar os veículos, a movimentação de pessoal, informando à garagem/empresa quaisquer diferenças no serviço. O fiscal, também, realiza o trabalho de controle e verificação no tocante aos modos e às condições de operação das linhas durante a circulação dos veículos. Essa relação de controle, vigilância e punição, muitas vezes, gera tensões (Prange, 2011), e isso pode indicar que tal fiscalização constante deixe o motorista pouco à vontade, por conseguinte, distanciando-o dos passageiros, ou, então, apenas, seguindo as regras estabelecidas, sem escutar e ver as particularidades dos passageiros; fazendo com que o motorista questione sua função e importância, fato que também está relacionado com a escala de trabalho e a indolência, pois os motoristas não possuem controle sobre a escala de trabalho.

O sentimento de Indolência, também, está relacionado com o estressor Pressão e responsabilidade que o motorista sente ao transportar passageiros ou trafegar pelas vias urbanas cumprindo horários pré-determinados de trajetos. Essa pressão pela responsabilidade pela vida de passageiros, cuidados com próprio veículo e o de terceiros (Torres, 2018), não raras vezes, ocasiona tensões nas relações interpessoais, pois alguns passageiros também o pressionam e o responsabilizam pelos possíveis atrasos em seus compromissos.

Percebeu-se que quanto menor era o tempo de profissão, maior era o distanciamento do motorista com os passageiros, os fiscais, os colegas de trabalho - como cobradores e auxiliares de tráfego. Dessa forma, pôde-se entender que, com pouco tempo de profissão, o motorista pode ser inseguro no seu relacionamento com os passageiros, mas, com a experiência, passa a ganhar a confiança de muitos deles, principalmente daqueles que fazem uso diário das linhas, conhecidos como passageiros efetivos, com os 
quais passam a criar um vínculo em razão do convívio. De acordo com Farber (1991), as expectativas, por vezes, irrealísticas dos novos profissionais em relação ao seu trabalho e ao retorno a ser obtido dele, também, podem ser fatores geradores de Burnout no início da carreira, pois os jovens, por vezes, envolvem-se com a profissão com elevadas expectativas e, muitas vezes, frustram-se. Outra possibilidade explicativa desse resultado, também, pode ser devido à formação insuficiente dos profissionais para aspectos como as relações interpessoais no trabalho (Rudow, 1999).

Relativamente à dimensão da Culpa, caracterizada pela cobrança social quanto ao comportamento e às expectativas profissionais (Gil-Monte, 2005), foi identificado que quanto maior era a percepção do estressor Relacionamento com os fiscais da empresa, maior era o sentimento de culpa, relação essa já identificada, na literatura, por Almeida (2002) e Silva e Zavarize (2017). Esse resultado pode ser entendido pelo fato de os fiscais das empresas de transporte coletivo de passageiros serem os responsáveis por fiscalizar os motoristas e identificar possíveis situações de desvio na conduta, como passageiros sem pagar passagem ou que não apresentam os documentos conforme a empresa solicita, o uso inadequado de uniforme, entre outras questões. No relacionamento com os fiscais, pode-se destacar o reconhecimento conferido pelos motoristas ao poder desses profissionais e a consequente frustração pela impossibilidade de controle de sua própria atividade de trabalho (Battiston, Cruz, \& Hoffmann, 2006). Na perspectiva de Sato (1995), o trabalhador, ao não ter controle sobre o trabalho, coloca-se em uma posição que o obriga a submeter-se a situações tensas como ser fiscalizado e vigiado de forma bastante próxima e constante por passageiros, fiscais e outros motoristas.

O tempo de profissão relacionou-se positivamente com esta dimensão, logo, quanto mais tempo de profissão o motorista apresentava, menos sentimentos de culpa tinha. Esse resultado pode ser entendido pelo fato de os profissionais mais jovens sofrerem muitas cobranças e apresentarem maior ansiedade no início da carreira, pois precisam conquistar o reconhecimento e provar sua capacidade para se sentirem mais seguros e respeitados no ambiente de trabalho, o que pode gerar muita ansiedade, estresse e esgotamento profissional (Carlotto \& Câmara, 2007; Dallacosta, 2014). Por fim, pode-se pensar que a maior pressão por responsabilidade assim como o estressor relacionamento com fiscais aumenta o sentimento de culpa, provavelmente, pelo fato dos motoristas sentirem-se cobrados por usuários e fiscais, não raras vezes, por questões do cotidiano que independem de sua capacitação profissional.

\section{Conclusão}

Os resultados deste estudo identificaram um modelo preditivo para as dimensões de Burnout constituído por variáveis sociodemográficas (menor idade), laborais (menor tempo de profissão, menor tempo de intrajornada) e estressores ocupacionais e psicossociais (maior percepção dos estressores: escala de trabalho, condições ambientais, relacionamento com passageiros idosos, relacionamento com fiscais, riscos de assaltos, ambiguidade de papéis e pressão do grau de responsabilidade).

Forças, limitações e sugestões de novos estudos. Como forças do estudo, destaca-se a utilização de um consistente modelo teórico utilizado em diferentes estudos internacionais e nacionais, e de instrumentos adaptados para o contexto brasileiro que obtiveram adequados índices de confiabilidade na amostra investigada. A magnitude de efeito para a análise estatística variou de média a elevada, indicando que os resultados obtidos, possivelmente, também, possam ser encontrados na população-alvo.

O estudo apresenta limitações que devem ser consideradas na apreensão de seus resultados. A primeira diz respeito ao tipo de delineamento de natureza transversal, que impossibilita a análise de relações causais. A segunda deve-se à utilização de medidas de autorrelato, que, por vezes, podem ocasionar um viés de desejabilidade social gerado por algumas questões relacionadas à dimensão de Indolência, pois o trabalhador receia expor-se a assumir que trata seus usuários com indiferença e que os considera desagradáveis. A terceira diz respeito à regionalidade da amostra, pois os participantes desenvolvem suas atividades em determinada região de um estado, e esse aspecto pode apresentar características de trabalho e trânsito distintas as de outras cidade e regiões do país.

Desse modo, considerando ser este um dos poucos estudos nacionais sobre a SB em motoristas, sugere-se a sua replicação com amostra nacional estratificada por regiões, incluindo, também, novas variáveis como estilos de liderança com o intuito de aumentar o poder explicativo do modelo obtido. Por ser um estudo transversal, seria importante que pesquisadores investigassem a $\mathrm{SB}$ e seus preditores mediante delineamentos longitudinais a fim de avaliar o comportamento e a estabilidade do modelo preditivo.

Implicações para a prática. Assim, ao ampliar o conhecimento sobre Burnout em motoristas de transporte coletivo de passageiros, é possível planejar uma prevenção a esse tipo de adoecimento ocupacional. Nesse sentido, pode-se pensar em ações preventivas de minimização dos impactos laborais que funcionem como preditores da Síndrome de Burnout, ações voltadas para a melhoria do desenho do cargo e das atividades de motorista.

Destarte, tem-se a sugestão de treinamentos a motoristas mais jovens e com menos tempo de profissão para auxiliá-los quanto à segurança no trabalho, por conseguinte, aumentando a autoconfiança e trabalhando com suas expectativas e frustrações pertinentes à profissão com o intuito de que possam se sentir mais motivados a alcançar suas metas. Por isso são necessárias ações efetivas como o acompanhamento introdutório funcional para sanar possíveis dúvidas sobre a profissão, bem como compartilhamentos de experiências.

Quanto aos estressores ocupacionais, pode-se pensar em ações para a adequação das escalas de trabalho visando a uma melhor organização do trabalhador para desenvolver e manter o equilíbrio entre trabalho e vida pessoal/familiar, fator fundamental para a qualidade de vida geral e laboral. É possível, ainda, pensar em um trabalho conjunto com o setor de fiscalização, visto que o relacionamento dos motoristas com os fiscais tem sido uma das variáveis explicativas da SB. É necessário verificar com as empresas tal possibilidade e, assim, realizar oficinas e treinamentos com os fiscais a fim de desenvolver novas maneiras de abordar os motoristas.

No que tange aos estressores psicossociais, como a ambiguidade de papéis, sugere-se ações voltadas para o redesenho do cargo para que o motorista realize somente as funções atinentes ao seu cargo, o que também trabalharia a pressão do grau de responsabilidade. Sob tal perspectiva é possível trabalhar, preventivamente, as formas de enfrentamento aos estressores com foco no problema.

Por fim, seria importante executar intervenções em âmbito estadual, como a divulgação, para melhor entendimento, da lei da gratuidade ou parcialidade do pagamento de pessoas com mais de 65 anos, com o objetivo de evitar constrangimentos aos motoristas, passageiros idosos e usuários. Outra intervenção seria o desenvolvimento de políticas públicas em termos de segurança para evitar os recorrentes assaltos aos coletivos e que colocam em risco a vida dos motoristas, assim como a preservação e manutenção das vias públicas.

\section{Referências}

Almeida, N. D. V. (2002). Contemporaneidade X Trânsito: reflexão psicossocial do trabalho dos motoristas de coletivo urbano. Psicologia: Ciência e Profissão, 1(3), 62-69. https://doi.org/10.1590/S1414-98932002000300010 
Alonso, F., Cendales, B., Gómes, V., \& Useche, S. A. (2018). Working conditions, job strain, and traffic safety among three groups of public transport drivers. Safety and Health at Work, 9(4), 454-461. https://doi.org/10.1016/i. shaw.2018.01.003.

Battiston, M., Cruz, R. M., \& Hoffmann, M. H. (2006). Condições de trabalho e saúde de motoristas de transporte coletivo urbano. Estudos de Psicologia (Natal), 11(3), 333-343. https://doi.org/10.1590/S1413-294X2006000300011

Bigattão, M. A. (2005). O estresse em motorista no transporte coletivo de ônibus urbano em Campo Grande (Dissertação de mestrado). Recuperado de https://site.ucdb. $\mathrm{br} / \mathrm{public} / \mathrm{md}$-dissertacoes/7746-o-stress-em-motoristas-no-transporte-coletivo-de-onibus-urbano-em-campo-grande.pdf

Brasil. Ministério do Trabalho. (2015). Classificação Brasileira de Ocupações do Ministério do Trabalho. Recuperado de: http://www.mtecbo.gov.br/cbosite/pages/ downloads.jsf

Brasil. Lei no 12.619, de 30 de abril de 2012. Dispõe sobre o exercício da profissão de motorista; altera a Consolidação das leis do Trabalho (CLT). Recuperado de http://www.planalto.gov.br/ccivil 03/ Ato2011-2014/2012/Lei/ L12619.htm

Carlotto, M. S., \& Câmara, S. G. (2007). Preditores da síndrome de burnout em professores. Psicologia Escolar e Educacional, 11(1), 101-110.

Chung, Y. S., \& Wong, J. T. (2012). Developing effective professional bus driver health programs: An investigation of self-rated health. Accident Analysis and Prevention, 43(6), 2093-2103. https://doi.org/10.1016/j.aap.2011.05.032

Dallacosta, F. M. (2014). Avaliação do nivel de satisfação do trabalho e dos sintomas de burnout em docentes da área de saúde. Tese de Doutorado, Faculdade de Medicina, PUCRS, Porto Alegre.

Farber, B.A. (1991). Crisis in education. Stress and burnout in the American teacher. São Francisco: Jossey-Bass Inc.

Ferreira, M. C., Milfont, T. L., Silva, A. P. C., Fernandes, H. A., Almeida, S. P., \& Mendonça, H. (2015). Escala para avaliação de estressores psicossociais no contexto laboral: construção e evidências de validade. Psicologia: Reflexão e Crítica, 28(2), 340-349. https://doi.org/10.1590/1678-7153.201528214

Field, A. (2009). Descobrindo a estatística usando o SPSS-2. Porto Alegre: Artmed.

Gil-Monte, P. R. (2005). El sindrome de quemarse por el trabajo (burnout). Una enfermidad laboral en la sociedad del bienestar. Madrid: Pirâmide.

Gil-Monte, P. R. (2011). CESQT: Cuestionario para la evaluación del síndrome de quemarse por el trabajo. Madrid: TEA.

Gil-Monte, P. R., Carlotto, M. S., \& Câmara, S. G. (2011). Prevalence of burnout in a sample of Brazilian teachers. The European Journal of Psychiatry, 25(4), 205-212. https://doi.org/10.4321/s0213-61632011000400003

Gil-Monte, P. R., Carlotto, M. S., \& Câmara, S. G. (2010). Validação da versão brasileira do "Cuestionario para la Evaluación del Síndrome de Quemarse por el Trabajo” em professores. Revista de Saúde Pública, 44(1), 140-147. https://doi.org/10.1590/S0034-89102010000100015

Lámbarry, F., Trujillo, M. M., \& Cumbres, C. G. (2016). Stress from an administrative perspective in public transport drivers in Mexico City: Minibus and metrobus. Estudios Gerenciales, 32(139), 112-119. https://doi. org/10.1016/i.estger.2016.02.003

Lima, A. R. De M., Lima, A. K. M., Silva, A. K. L. (2018). Síndrome de Burnout: um olhar para os motoristas de transporte coletivo que exercem dupla função na cidade de Natal - RN. Revista Científica Multidisciplinar Núcleo do Conhecimento, 5, 129-143. Recuperado de https://www.nucleodoconhecimento.com.br/psicologia/dupla-funcao

Makowiec-Dąbrowska, T., Gadzicka, E., Siedlecka, J., Szyjkowska, A., Viebig, P., \& Bortkiewicz, A. (2019). Climate conditions and work-related fatigue among professional drivers. International Journal of Biometeorology, 63(2), 121-128. Recuperado de https://link.springer.com/article/10.1007/ s00484-018-1643-y

Marôco, J. (2007). Análise estatística com utilização do SPSS (3.ed.). Edições. Sílabo.

Matias, C. A., Sales, M. M. (2017). Malabarismo no trânsito: o trabalho do motorista do transporte coletivo em dupla função. Pretextos-Revista da Graduação em Psicologia da PUC Minas, 2(4), 157-174. Recuperado de http://periodicos. pucminas.br/index.php/pretextos/article/view/15250

Matos, M. G., Moraes, L. F. R., \& Pereira, L. Z. (2015). Análise do estresse ocupacional em motoristas de coletivo urbano na cidade de Belo Horizonte. Revista Gestão \& Tecnologia, 15(1), 256-275. Recuperado de http://revistagt. fpl.edu.br/get/article/view/758

Maslach, C., \& Leiter, M. P. (2016). Understanding the burnout experience: recent research and its implications for psychiatry. World Psychiatry, 15(2), 103-111. https://doi.org/10.1002/wps.20311

Maslach, C., Schaufeli, W. B., \& Leiter, M. P. (2001). Job burnout. Annual Review Psychology, 52(1), 397-422. https://doi.10.1146/annurev.psych.52.1.39

Moraes, T. D., Santorum, K., Souza, F. V. B. de, Ávila, L. R, \& Vieira, S. S. (2017). Considerações sobre o ofício de dirigir ônibus no Brasil: uma revisão de literatura. Estudos Interdisciplinares de Psicologia, 8(2), 76-99. https://doi.10.5433/ 2236-6407.2016v8n1p76

Nóbrega, J. R. S. (2015). Sindrome de Burnout em motoristas de ônibus no município de João Pessoa -PB (Dissertação de mestrado). Recuperado de http://biblioteca. unisantos.br: $8181 /$ bitstream/tede/1842/2/Joao $\% 20$ Ricardo $\% 20$ Soraes $\% 20$ Nobrega.pdf
Olivares, V. E. F., Wilke, C. J., Mena L., M., \& Lavarello, J. S. (2013). Estudios sobre burnout y carga mental en conductores del transporte público de Chile (Transantiago). Ciencia \& Trabajo, 15(48), 173-178. https://doi.org/10.4067/S071824492013000300011.

Oliveira, A. C. F., \& Pinheiro, J. Q. (2007). Indicadores psicossociais relacionados a acidentes de trânsito envolvendo motoristas de ônibus. Psicologia em Estudo, 12(1), 171-178. https://doi.org/10.1590/\$1413-73722007000100020

Prange, A. P. L. (2011). “Quem dá mais, cobra mais!” Uma análise das normas antecedentes do ofício de motorista de ônibus em um contexto específico. Estudos e Pesquisa em Psicologia, 11(2), 551-565. https://doi.org/10.12957/ epp. 2011.8394

Quirino, G. S., \& Villemor-Amaral, A. E. (2015). Relação entre estresse e agressividade em motoristas profissionais. Revista Psicologia e Saúde, 7(2), 125-132. Recuperado de http://pepsic.bvsalud.org/scielo.php?script=sci arttext\&pi$\mathrm{d}=\mathrm{S} 2177-093 \mathrm{X} 2015000200006 \& \operatorname{lng}=\mathrm{pt} \& \mathrm{t} \operatorname{lng}=\mathrm{pt}$

Rio Grande do Sul. Lei n 10.982, de 06 de agosto de 1997. Modificada pela Lei $n^{\circ}$ 11.338, de 17 de junho de 1999. Atualizada. Determina a concessão de desconto no valor das passagens rodoviárias intermunicipais no Estado do Rio Grande do Sul. Recuperado de https://www.daer.rs.gov.br/upload/arquivos/201607/22143918-lei-10-982.pdf

Rudow, B. (1999). Stress and burnout in the teaching profession: European studies, issues, and research perspectives. Em R. Vanderbergue \& M. A. Huberman (Orgs.), Understanding and preventing teacher burnout: A source book of international practice and research (pp. 38-58). Cambridge: Cambridge University Press.

Sato, L. (1995). A representação social do trabalho penoso. Em M. J. Spink (Org.), O conhecimento do cotidiano: as representaçoes sociais na perspectiva da Psicologia Social (pp. 188-211). São Paulo: Brasiliense. Recuperado de https://pdfs.semanticscholar.org/2d26/fcdce614c53747f0a301aaef33eeb2ce9b34.pdf

Serrano-Fernández, M. S., Boada-Grau, J., Robert-Sentís, L., Vigil-Colet, A., \& Assens-Serra, J. (2019). Predictive power of selected factors over driver stress at work. International Journal of Occupational Safety and Ergonomics. 26, 1-9. https://doi.org/10.1080/10803548.2019.1613812

Silva, L. F., \& Zavarize, C. A. (2017). Incidência de fatores que ocasionam estresse em motoristas de ônibus: uma comparativa entre o transporte urbano e de fretamento. Revista Cientifica Faculdades do Saber, 2(3), 168-184. Recuperado de https://rfs.emnuvens.com.br/rfs/article/view/26

Souza, M. B., Liberal, H. K. A., \& Saburido, R. A. L. (2016). Motorista de ônibus urbano: o estresse na profissão. Recife: Fundação Dom Cabral; Instituto de Transporte e Logística. Recuperado de https://repositorio.itl.org.br/jspui/ bitstream $/ 123456789 / 49 / 1 / \mathrm{O} \% 20$ motorista $\% 20$ do $\% 20$ ônibus $\% 20$ urbano $\% 20-\% 200 \% 20$ estresse $\% 20$ na $\% 20$ profissão.pdf

Tavares, F. A. (2010). Estresse em motoristas de transporte coletivo urbano por ônibus (Tese). Uberlândia: Universidade Federal de Uberlândia. Recuperado de: http://repositorio.ufu.br/handle/123456789/17095

Torres, M. A. S. (2018). Os sentidos do trabalho: autoconfrontação com motoristas de ônibus do transporte coletivo urbano de Curitiba (Dissertação de mestrado). Recuperado de http://repositorio.utfpr.edu.br:8080/ispui/bitstream/1/3872/1/CT PPGA M Torres $\% 2 \mathrm{C} \% 20$ Mariã $\% 20$ Aparecida $\% 20$ Santos 2018.pdf

Tse, J. L. M., Flin, R., \& Mearns, K. (2006). Bus driver well-being review: 50 Years of research. Transportation Research Part F.: Traffic Phychology and Behaviour Journal, 9(2), 89-114. https://doi.org/10.1016/j.trf.2005.10.002

Useche, S., Cendales, B., Alonso, S., \& Serge, A. (2017). Comparing job stress, burnout, health and traffic crashes of urban bus an BRT drivers. American Journal of Applied Psychology, 5(1), 25-32. https://doi.10.12691/ajap5-1-5

Useche, S. A., Alonso, F., Cendales, B. E. Autukevičiūtè, R. , \& Serge, A. (2017). Burnout, job strain and road accidents in the field of public transportation: The case of city bus drivers. Journal of Environmental and Occupational Science, 6(1), 1-7. https://doi.org/10.5455/jeos.2017020207463

Valarmathi, D. (2019). A study on occupational stress of bus drivers and its prevention. International Journal of Basic and Applied Research, 9(4), 23-27. Recuperado de http:/ /www.pragatipublication.com/assets/uploads/ doc/73817-23-27.16472.pdf

Zanelato, L. S., \& Oliveira, L. C. (2008). Fatores estressantes presentes no cotidiano dos motoristas de ônibus urbano (Manuscrito não publicado). Recuperado de https://slidex.tips/download/fatores-estressantes-presentes-no-cotidiano-dos-motoristas-de-onibus-urbano

\section{Informações sobre as autoras:}

Gabriela Cristine Neumann

E-mail: neumann_gabriela@yahoo.com.br

\section{Mary Sandra Carlotto}

E-mail:mscarlotto@gmail.com 